\section{Clinical Research: Why It Matters in 2018}

At the 2017 Canadian Society of Internal Medicine conference, I had the privilege of receiving the Dr. David Sackett Senior Investigator Award. I wish to share some key points from a lecture about clinical research and why it (still) matters in 2018 I gave at that time. It is directed at aspiring clinical investigators and early-career physicians who may be considering a full or partial career in clinical research but may be uncertain about whether it is "worth it". As you read this, I will strive to convince you that clinical research does matter and whether you decide to just dip your toe into the shallows or to dive right into the deep end, it will enrich your life and make you a better doctor.

First, let us consider reasons not to make research part of your work activities. I have heard aspiring researchers and even seasoned colleagues offer the following deterrents: "There are too many administrative barriers" or "I am not good at writing, especially grants". My favourite is: "All the important questions have already been answered". Although I agree that in 2018 clinical research has a denser administrative component (e.g., fifteen-page vs. one-page consent forms) and there are more hoops to jump through (e.g., contracts and legal review) than previously, other research opportunities have emerged. Despite the increased administration associated with clinical research, these changes are positive as they provide patients and researchers more checks and balances to allow the highest possible standards to conduct research. As for the claim about a shrinking research landscape, one can rebut it by saying that addressing one research question will create new questions. Moreover, in 2018, new fields of research have emerged that may not have been as noticeable in the past. These include research on quality improvement initiatives (e.g., effectiveness of Choosing Wisely), big-data research (e.g., using linked administrative databases to assess intervention and drug-related harm), and research related to knowledge translation (e.g., is the evidence getting through). Addressing whether and how we are delivering health care and determining if it is done in an efficient manner is of paramount importance in 2018. Moreover, these new areas (combined with the more traditional clinical research domains) will gain increasing traction among funding agencies when tensions increase relating to an ageing population of health care consumers and the limited resources to address these increasing needs.

For aspiring young clinicians who are including research as part of their career plans may I suggest a few dos and don'ts.

1. Do think of your own ideas for projects: You are more likely to be committed if you have ownership of the project. Don't quickly accept that your ideas lack merit: Be respectful but wary of naysayers.

2. Do trust your supervisor's opinions: Their experience will guide you in the right path. Don't always trust your supervisor's opinions: Their experience may be biased towards their own priorities.

3. Do think big: Be ambitious in your goals; ideas do not cost anything and curiosity is of paramount importance. Don't think too big: Temper ambition with practicality and park more ambitious projects for later.
4. Do try to be in a good research environment: The environment will enable exposure to different opportunities. Don't be discouraged if you in a small centre: Ideas and one or two committed advocates matter.

5. Do maintain your integrity: Once lost, integrity is difficult to regain and not worth the risk of losing. Don't burn bridges: The research world is small and there is no value in antagonizing colleagues or institutions.

Let us now consider why research should be built into your career as an internist. For academic internists, it provides a vehicle towards cultivating expertise and being on the cutting edge of new developments in a chosen field which, in turn, will provide a substrate for academic career advancement. For community internists, a research focus can provide a foundation for leadership and administrative advancement. Apart from the "getting ahead" aspect, a career that includes research provides other benefits such as the ongoing reward and gratification of intellectual stimulation and the interaction with colleagues at a stateof-the-art level. However, the most important benefit is the effect it has on the care of your patients: by engaging in research, we are constantly asking questions of what we do, how we do it, and why we do it. This critical self-evaluation of how we practice medicine - itself a by-product of a research environment - enables us to better communicate with and care for our patients.

DOI: 10.22374/cjgim.v13i2.294

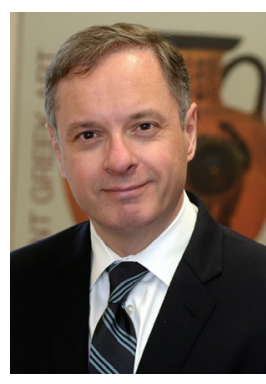

Jim Douketis, MD

Editor-in-Chief 